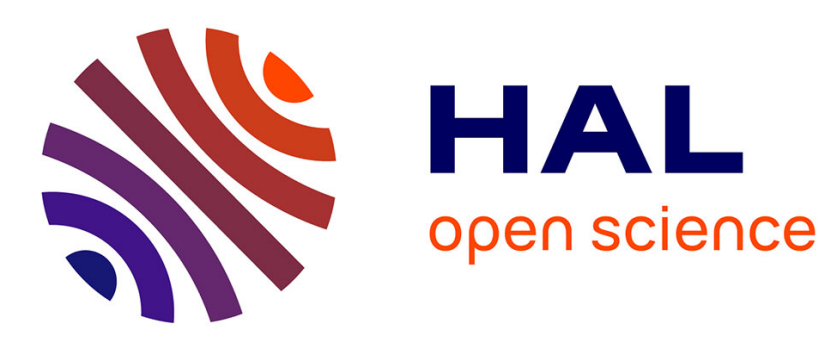

\title{
Marie-Christine Labourdette, Les musées de France Marie-Christine Bordeaux
}

\section{To cite this version:}

Marie-Christine Bordeaux. Marie-Christine Labourdette, Les musées de France. Culture et Musées, 2016, pp.150-151. 10.4000/culturemusees.1042 . hal-02022285

\section{HAL Id: hal-02022285 \\ https://hal.science/hal-02022285}

Submitted on 17 Feb 2019

HAL is a multi-disciplinary open access archive for the deposit and dissemination of scientific research documents, whether they are published or not. The documents may come from teaching and research institutions in France or abroad, or from public or private research centers.
L'archive ouverte pluridisciplinaire HAL, est destinée au dépôt et à la diffusion de documents scientifiques de niveau recherche, publiés ou non, émanant des établissements d'enseignement et de recherche français ou étrangers, des laboratoires publics ou privés. 


\section{LECTURES}

Marie-Christine Labourdette

Les Musées de France. Paris : PUF (Coll. Que sais-je ?). 2015. 127 p.

Si les normes qui entourent la conception et l'activité des musées sont nombreuses, l'appellation «musée » est restée libre et ouverte. Chacun peut fonder un musée, rappelle l'auteure de cet ouvrage, car le musée est « une instance protéiforme qui peut traiter indifféremment du rapport à toutes les formes d'histoire, de la découverte de réalités géographiques et sociologiques diverses ou de l'étude du vivant ou de bien d'autres thèmes » (p. 4). Cependant, la France a défini en 2002 un cadre légal, qui fonde un corpus institutionnel d'environ 1200 établissements. L'ouvrage de synthèse de Marie-Christine Labourdette, directrice des Musées de France au ministère de la Culture et de la Communication, prolonge et complète celui de Jacques Sallois publié en 2004 chez le même éditeur et sous le même intitulé. Il s'attache, plus de dix ans après sa création, à ce cadre - le label "Musée de France »- et au paysage, très contrasté, malgré l'ambition unificatrice du label, des musées qui en relèvent.

L'ouvrage débute par un rapide rappel historique de l'émergence de la notion de collection publique, à partir d'un triple héritage - État, collectivités, particuliers - qui permet de comprendre le caractère hétérogène des Musées de France, aussi bien dans leurs thématiques, dans leur étendue que dans leurs statuts. Ces musées sont issus d'une habile synthèse révolutionnaire entre ancrages et particularismes locaux, d'une part, et «part sacrée » de l'héritage de la nation (p. 14), d'autre part. Dans leur grande majorité (82\%), ces musées sont sous la tutelle des collectivités territoriales. L'ordonnance du 13 juillet 1945 avait établi un classement provisoire des musées de France, en trois catégories : nationaux, classés et contrôlés. Mais cette législation nécessitait d'être modifiée, car elle comportait des lacunes importantes, notamment du côté des musées d'État rattachés à d'autres ministères que celui de la Culture. De plus, elle privilégiait les musées de beaux-arts et ne définissait pas de règle professionnelle commune à ce réseau d'établissements. Elle s'est donc trouvée en décalage important, au moment du «boom » des musées au cours des années 1980, ou de l'émergence des musées de société dans les années 1970, avec la réalité et la diversité des musées français. L'ouvrage montre ensuite - deuxième partie - comment, au-delà des dispositions légales, la loi de 2002 modifie profondément la politique des musées, aux deux sens du terme : politique nationale et politique interne. Elle inscrit de manière explicite les musées dans les attentes de la société contemporaine, en affirmant par exemple l'obligation d'une stratégie de médiation, ce qui fait citer pour la première fois la médiation culturelle dans un texte réglementaire. Elle formalise également l'impératif d'un projet scientifique et culturel, étendu à tous les établissements labellisés après une première expérimentation au Musée de Picardie en 1996. La loi permet aussi d'organiser la décentralisation, mettant fin à la distinction entre musées classés (au nombre de 35 en 2002) et musées contrôlés (1100 à la même époque). Elle offre enfin de nouveaux outils de gestion, notamment celui de l'EPCC (établissement public de coopération culturelle) qui permet de faire sortir les musées de la gestion en régie municipale, condition d'une modernisation souvent nécessaire.

Au niveau national, elle suscite un important mouvement d'autonomisation par rapport au système mutualiste de la RMN (Réunion des musées nationaux), qui sera profondément modifié en 2011 avec l'établissement public du Grand Palais. L'exercice de la tutelle de l'État sur le service public des musées évolue en 2009. L'État joue un rôle plus stratégique, en coordonnant les politiques des établissements, en veillant à leur complémentarité et à leur non-concurrence (p. 53). Définition des priorités en matière de politiques des publics, circulation des collections nationales, axes structurants de la politique scientifique et 
culturelle des musées, telles sont quelques-unes de ces nouvelles orientations.

Nous passerons rapidement sur la troisième partie, détaillée, mais assez factuelle, qui aborde le principe d'inaliénabilité, l'inventaire, le récolement, les acquisitions, la circulation, la gestion des réserves et la sûreté des collections. La quatrième partie aborde en effet des enjeux actuellement cruciaux pour les musées : les publics et la médiation culturelle. Elle met en avant les chiffres, parfois spectaculaires, de fréquentation des musées aujourd'hui. Elle décrit les efforts réalisés en matière d' «expérience de visite» (p. 91) avec une grande inventivité, au sein des musées et hors les murs, au-delà des pratiques banalisées d'accueil ou de visite guidée, visant des publics variés, accueillis dans leurs singularités. Ces chiffres de fréquentation et la multiplication de ces dispositifs démontrent, s'il en était encore besoin, que le discours aujourd'hui encore très prégnant sur la crise de la démocratisation culturelle mérite d'être abordé avec prudence et distance, tant le potentiel de popularisation de la culture dans le domaine du patrimoine et des musées offre, aujourd'hui encore, de perspectives.

Après un développement qui aurait pu être plus important - au regard des pratiques actuelles - sur les usages du numérique, l'ouvrage conclut sur le rôle des musées en matière d'aménagement, de développement, et de rayonnement des territoires. Sont ainsi abordés le soutien financier de l'État, la création d'antennes en région, la délocalisation du MuCEM, les partenariats avec les collectivités, le rôle des musées dans la coopération culturelle décentralisée, dans l'axe nord-sud, mais aussi en direction de l'Asie ou de l'Amérique du Sud. Le développement des stratégies de marque de certains musées à l'international est traité sous l'angle de l'exportation de l'expertise française. En revanche, certains défis sociétaux et anthropologiques auxquels les musées sont confrontés, notamment ceux qui bénéficient du label Musée de France, sont absents de la perspective proposée : collections humaines, œuvres et biens issus de spoliations, protection et gestion des réserves, réalité et ambition des projets scientifiques des musées labellisés. De même, la crise des financements publics de la culture, sans doute trop récente, n'est pas abordée dans l'ouvrage. Cela appelle d'autres publications, dans d'autres espaces éditoriaux.

MARIE-CHRISTINE BORDEAUX Université Grenoble Alpes 